\title{
Fenologia reprodutiva de Syagrus romanzoffiana (Cham.) Glassman (Arecaceae) em Floresta Atlântica no sul do Brasil
}

\author{
Romualdo Morelatto Begnini ${ }^{1 *}$ \\ Fernanda Ribeiro da Silva ${ }^{1}$ \\ Tânia Tarabini Castellani ${ }^{2}$ \\ Universidade Federal de Santa Catarina, Centro de Ciências Biológicas \\ ${ }^{1}$ PPG em Biologia Vegetal, Caixa Postal 476, CEP 88040-970, Florianópolis - SC, Brasil \\ ${ }^{2}$ Laboratório de Ecologia Vegetal, Departamento de Ecologia e Zoologia \\ *Autor para correspondência \\ romomb@gmail.com
}

Submetido em 21/10/2012

Aceito para publicação em 29/07/2013

\section{Resumo}

Este estudo avaliou a fenologia reprodutiva de Syagrus romanzoffiana em área de vegetação secundária de Floresta Atlântica no Parque Municipal da Lagoa do Peri, Florianópolis, Santa Catarina, Brasil. As avaliações foram feitas a cada 30 dias, em 39 palmeiras reprodutivas, de junho de 2006 a julho de 2008. Dois eventos de floração foram registrados, um de novembro de 2006 a fevereiro de 2007 e outro de outubro de 2007 a março de 2008, com maior intensidade em dezembro de 2006 (média \pm dp) $(0,38 \pm 0,63$ inflorescências/planta) e janeiro de $2008(0,59 \pm 0,55)$. A frutificação foi contínua, com frutos verdes presentes em todos os 26 meses e maior intensidade em março de 2008 (1,64 $\pm 1,11$ infrutescências/planta). Os frutos maduros estiveram presentes de forma descontínua, podendo ocorrer entre março e novembro, com as maiores intensidades em julho de 2006 $(0,56 \pm 0,50)$ e em julho de $2008(0,51 \pm 0,51)$. As médias mensais de inflorescências e de infrutescências maduras por planta apresentaram correlações significativas com o fotoperíodo, a precipitação e a temperatura dos meses correntes do período de estudo. Syagrus romanzoffiana apresentou variações na intensidade reprodutiva entre 2006 e 2008, com períodos de maior e de menor intensidade.

Palavras-chave: Floração; Frutificação; Intensidade reprodutiva; Palmeira; Variáveis climáticas

\section{Abstract}

Reproductive phenology of Syagrus romanzoffiana (Cham.) Glassman (Arecaceae) in Atlantic Forest, in southern Brazil. This study evaluated the reproductive phenology of Syagrus romanzoffiana in an area of secondary vegetation of Atlantic Forest in Parque Municipal da Lagoa do Peri, Florianópolis, Santa Catarina, Brazil. Evaluations were made every 30 days, for 39 reproductive palms, from June 2006 to July 2008. Two flowering events were recorded, one from November 2006 to February 2007 and another from October 2007 to March 2008. Flowering intensity was greater in December 2006 (mean $\pm \mathrm{sd})(0.38 \pm 0.63$ inflorescences/plant) and January $2008(0.59 \pm 0.55)$. Fruiting was continuous, with green fruits present during all 26 months of the study; intensity was greatest in March of 2008 (1.64 \pm 1.11 infructescenses/plant). Ripe fruits were discontinuously present, occurring between March and November, with the highest intensity of infructescences in July 2006 $(0.56 \pm 0.50)$ and July $2008(0.51 \pm 0.51)$. The monthly mean of inflorescences and mature infructescences per 
plant showed significant correlations with the photoperiod, rainfall and temperature during the months of the study period. The reproductive intensity of Syagrus romanzoffiana, between 2006 and 2008, varied with periods of greater and smaller intensity.

Key words: Climatic variables; Flowering; Fruiting; Palm; Reproductive intensity

\section{Introdução}

A fenologia estuda os eventos biológicos repetitivos, as causas de sua ocorrência e sua relação com os fatores bióticos e abióticos (TALORA; MORELLATO, 2000). Nos vegetais, ela abrange os padrões sazonais de floração, frutificação, queda e brotamento foliar (MANTOVANI et al., 2003; D'EÇA-NEVES; MORELLATO, 2004; RUIZ; ALENCAR, 2004), reunindo informações sobre o período de crescimento e reprodução, associado às variações climáticas ambientais (CALVI; RODRIGUES, 2005; SANTOS; TAKAKI, 2005). Entre as variáveis climáticas mais relacionadas à sazonalidade dos eventos fenológicos estão o fotoperíodo, a irradiação, a precipitação e o estresse hídrico (PIÑERO; SARUKHÁN, 1982; RATHCKE; LACEY, 1985; PEDRONI et al., 2002; BIANCHINI et al., 2006).

Em ambientes pouco sazonais, os fatores climáticos parecem ter menor influência sobre as fenofases do que em ambientes notadamente sazonais (MORELLATO; LEITÃO-FILHO 1990). Todavia, Morellato et al. (2000) sugerem que plantas tropicais têm a periodicidade de suas fenofases afetada por pequenas mudanças no comprimento do dia em climas sazonais, assim como em climas não sazonais quanto à temperatura e/ou precipitação.

A fenologia de espécies de palmeiras evidencia diferentes padrões e associações às variáveis climáticas. Na região sul do Brasil, a floração da palmeira Euterpe edulis Martius aconteceu de novembro a fevereiro, com picos em dezembro e janeiro e frutos maduros de maio a novembro (MANTOVANI; MORELLATO, 2000), já a palmeira Butia capitata (Martius) Beccari floresceu no inverno, com pico na primavera. A frutificação ocorreu no verão, sob alta temperatura e pluviosidade (ROSA et al., 1998).

As palmeiras são importantes espécies para animais frugívoros, por ofertar grandes quantidades de frutos ao longo do ano (SILVA et al., 2011; ZIMMERMANN et al.,
2011). Genini et al. (2009) ao avaliarem a importância das palmeiras na oferta de frutos aos frugívoros residentes em uma ilha antropizada, através da fenologia de espécies de palmeiras e demais espécies arbóreas, encontraram que as palmeiras e demais árvores têm um padrão fenológico sazonal; no entanto, a floração foi irregular ao longo do ano e os momentos de frutificação das palmeiras diferiram das outras espécies. As palmeiras também foram responsáveis pela oferta de mais de $80 \%$ da biomassa dos frutos produzidos, constituindo um importante recurso entre os meses de junho e agosto, período de baixa disponibilidade de frutos na Ilha Anchieta, sudeste do Brasil. Outros autores já vêm destacando a importância dessa família (HENDERSON et al., 2000; PERES, 2000; REIS; KAGEYAMA, 2003; TONHASCA JR., 2005), uma vez que estas plantas são consideradas recursos-chave para a comunidade de frugívoros em épocas de escassez de alimentos.

A palmeira Syagrus romanzoffiana (Cham.) Glassman apresenta a maior distribuição geográfica dentro deste gênero (BERNACCI et al., 2008), ocorrendo em grande parte da América do Sul, no Brasil, Paraguai, Argentina e Uruguai, em diversos habitats como florestas subtropicais e de araucárias, floresta atlântica, restingas, estepes, campos sujos e em florestas secundárias jovens, secundárias tardias e florestas maduras (GUIX; RUIZ, 2000; LORENZI, 2002; 2004). Seus frutos e sementes são importantes recursos para uma ampla variedade de aves e mamíferos, incluindo antas, porcos-do-mato, pacas, macacos, micos, coatis, gambás, tucanos e cracídeos (GUIX; RUIZ, 2000; GALETTI et. al., 2001; FLEURY; GALETTI, 2004; GIOMBINI et al., 2009). Por Syagrus romanzoffiana representar uma importante fonte de alimento para a fauna, esta é considerada uma espécie de grande relevância em fragmentos de Mata Atlântica (GALETTI et al., 1992; ALVES-COSTA, 2004; ZIMMERMANN et al., 2011).

Considerando as interações da palmeira $S$. romanzoffiana nos remanescentes florestais onde ela 
está presente e por tratar-se de uma importante espécie ornamental e frutífera, uma vez que foi relacionada como "plantas para o futuro" pelo Ministério do Meio Ambiente (ZIMMERMANN et al., 2011), este trabalho propôs-se a avaliar o comportamento fenológico reprodutivo desta palmeira em uma área de Floresta Atlântica secundária no sul do Brasil, visando responder: a) qual o padrão fenológico de Syagrus romanzoffiana? b) quais variáveis climáticas influenciam a fenologia desta palmeira? c) como se caracteriza a intensidade da floração e da frutificação e a atividade das plantas?

\section{Material e Métodos}

\section{Área de estudo}

O estudo foi realizado em área de vegetação secundária de Floresta Atlântica, com 1500 ha (SILVA, 2000; SIMONASSI, 2001), que constitui a maior fração do Parque Municipal da Lagoa do Peri (PMLP)

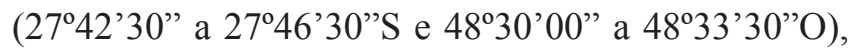
localizado na região sul da Ilha de Santa Catarina, Brasil. Para o acompanhamento fenológico foi utilizada uma trilha pré-estabelecida, com extensão de $2000 \mathrm{~m}$, em uma região de encosta dentro do PMLP. As espécies arbóreas mais frequentes no dossel da área de estudo são Syagrus romanzoffiana, Ficus spp., Miconia cabucu Hoehne, Guapira opposita (Vell.) Reitz, Schizolobium parahyba (Vell.) S.F. Blake, Mimosa bimucronata (DC.) Kuntze, Cupania vernalis Cambess., Cecropia glaziovii Snethl., Pera glabrata (Schott) Poepp. ex Baill. e Erythroxylum argentinum O.E. Schulz. No sub-bosque destacam-se Bactris setosa Mart., Piper spp., Psychotria spp., Heliconia velloziana Emygdio, Pavonia sepium A. St.-Hil., Leandra spp. e Clidemia hirta (L.) D. Don (D. B. Falkenberg, comunicação pessoal).

O clima local é classificado como Cfa (clima mesotérmico úmido), com chuvas distribuídas ao longo de todo o ano (CASTELLANI et al., 1999). Dados climáticos obtidos junto à Epagri/Ciram/Inmet para a região da Grande Florianópolis (estação São José, Santa Catarina, latitude $27^{\circ} 35^{\prime} \mathrm{S}$ e longitude $48^{\circ} 34^{\prime} \mathrm{O}$ e dois metros de altitude) mostram que a temperatura média anual fica em torno de $20,7^{\circ} \mathrm{C}$, com menor média em julho, $13,6^{\circ} \mathrm{C}$, e maior média em fevereiro, atingindo $25^{\circ} \mathrm{C}$ (Figura 1A). A média pluviométrica é de aproximadamente $1.730 \mathrm{~mm} / \mathrm{ano}$, com as maiores concentrações de chuva em janeiro e fevereiro e as menores em junho e agosto (Figura 1A). O fotoperíodo médio é $12,9 \mathrm{~h}$ de luz/dia, com os dias mais longos apresentando em média $14 \mathrm{~h}$, entre os meses de novembro e fevereiro, e os dias mais curtos 11 e $12 \mathrm{~h}$, entre os meses de maio a agosto (Figura 1B).

FIGURA 1: Caracterização climática para a região de Florianópolis, SC. (A) Precipitação média mensal (colunas) e temperatura média mensal (linha) para uma série temporal de 30 anos (1977-2007); (B) Fotoperíodo médio mensal do período de estudo (junho de 2006 a julho de 2008) e (C) Precipitação total mensal (colunas) e temperatura média mensal (linha) do período de estudo (junho de 2006 a julho de 2008). (Fonte: Epagri/Ciram/Inmet, São José-SC).
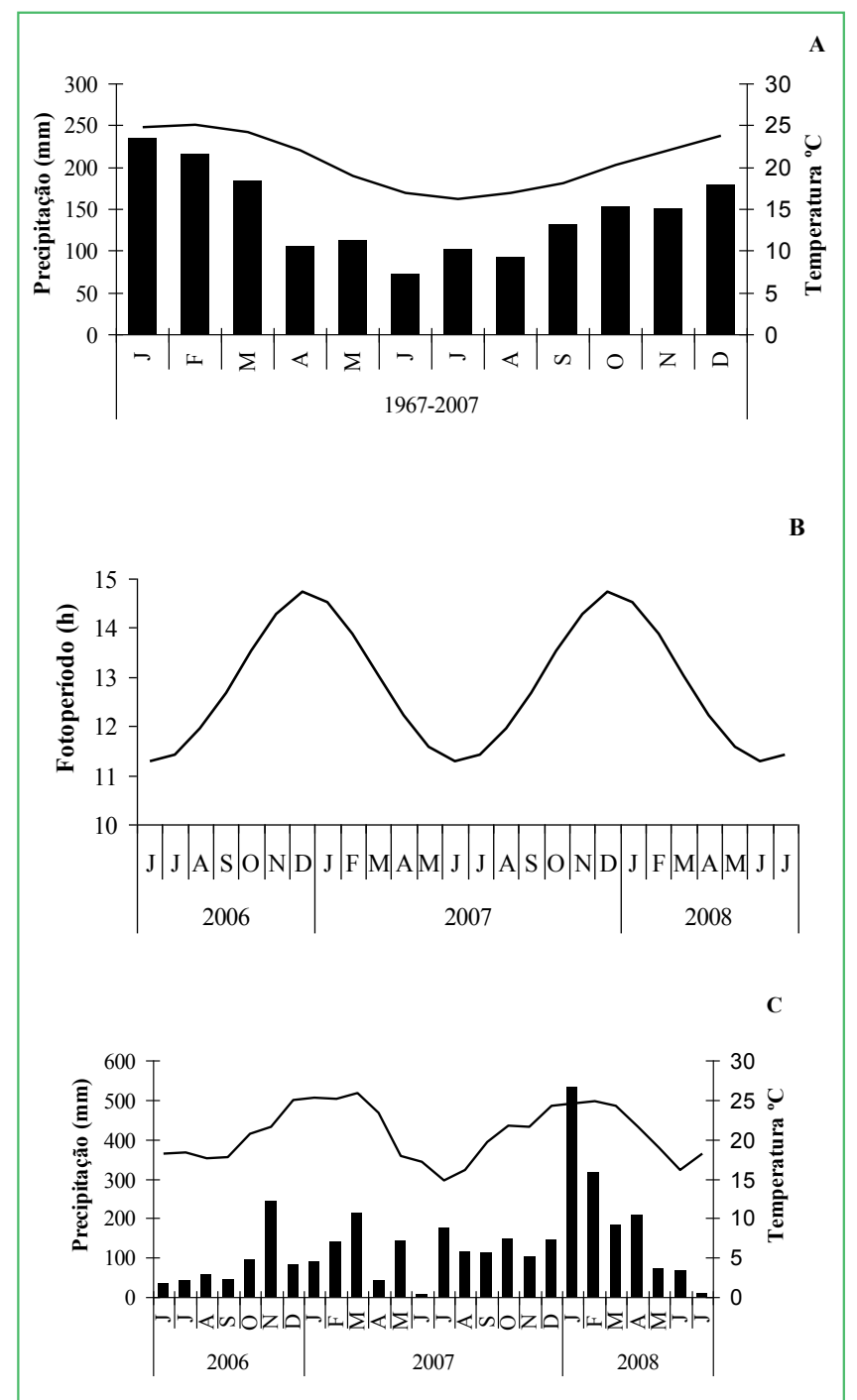
No período do estudo, a precipitação foi de 598,8 $\mathrm{mm}$ em 2006, 1.426,6 mm em 2007 e 1.390,5 mm em 2008 (Figura 1C). Segundo os critérios de Wright e van Schaik (1994), houve déficit hídrico (pluviosidade média inferior a $60 \mathrm{~mm}$ mensais) de junho a setembro de 2006 e em abril (41,2 mm) e junho (6,9 mm) de 2007. O mês de junho de 2007 foi o período de menor pluviosidade dos últimos 30 anos, enquanto que janeiro de 2008 (532,6 $\mathrm{mm}$ ) atingiu o segundo maior valor de precipitação dos últimos 30 anos. A temperatura média $\left(21,09^{\circ} \mathrm{C}\right)$ durante o período de estudo foi muito próxima da média climática de $30 \operatorname{anos}\left(20,7^{\circ} \mathrm{C}\right)$ (Figura 1A e 1C).

\section{Espécie estudada}

A palmeira Syagrus romanzoffiana (Cham.) Glassman, conhecida popularmente como jerivá, é uma espécie perene, heliófita, seletiva higrófita, com estipe isolado e cilíndrico, que pode atingir de 10 a 20 $\mathrm{m}$ de altura e 30 a $40 \mathrm{~cm}$ de diâmetro. A reprodução é exclusivamente sexuada, com inflorescência interfoliar em cacho pendente, ramificado, de 80 a $120 \mathrm{~cm}$ de comprimento (LORENZI, 2002; 2004; ZIMMERMANN et al., 2011). Produz cerca de 800 frutos por cacho (GALETTI et al., 1992), os quais são frutos do tipo drupa, globosos ou ovoides, de cor amarela ou alaranjada, com um fino exocarpo e um mesocarpo fibroso que envolve uma única semente. A semente é protegida por um endocarpo lenhoso que mede em torno de 2,4 por $1,6 \mathrm{~cm}$ (GALETTI et al., 1992; OLMOS et al., 1999).

\section{Fenologia da floração e frutificação}

Foram acompanhados 39 indivíduos de $S$. romanzoffiana para os registros fenológicos. A presença de evento reprodutivo foi o parâmetro escolhido para a seleção e marcação das palmeiras no mês de maio de 2006. As palmeiras monitoradas localizavam-se entre dois e $15 \mathrm{~m}$ da borda da trilha e desde um metro até mais de $100 \mathrm{~m}$ de distância entre elas.

As avaliações fenológicas foram feitas a cada 30 dias, de junho de 2006 a julho de 2008 (26 meses). Foram acompanhadas duas fenofases - I - floração - estendeu-se desde a visualização da inflorescência (cachos com flores em antese) até a queda das flores; e II - frutificação - subdividida em infrutescências verdes e infrutescências maduras, esta última iniciouse com a coloração amarela dos frutos e estendeu-se até o final da dispersão. Quando ocorreram frutos verdes e maduros na mesma infrutescência, estas foram consideradas como maduras. Em cada avaliação foram realizadas observações cuidadosas da copa das plantas, com o auxílio de binóculos Tasco ${ }^{\circledR}$ 10x30, onde fez se o registro do número de inflorescências e de infrutescências de cada palmeira.

Para a análise dos dados, quantificou-se o número mensal de inflorescências e de infrutescências de cada palmeira e suas respectivas médias. Estimou-se o índice de intensidade a partir da média mensal de cada fenofase. O índice de atividade foi calculado a partir da porcentagem de indivíduos que manifestaram determinado evento fenológico. A sincronia entre indivíduos foi feita levandose em conta o número de plantas que manifestaram ao mesmo tempo cada fenofase.

Para verificar a relação entre as estruturas reprodutivas presentes de junho de 2006 a julho 2008 (média mensal das inflorescências, das infrutescências verdes e das infrutescências maduras) e as variáveis climáticas (fotoperíodo médio mensal, temperatura média mensal e precipitação total mensal) foram utilizadas análises de correlação de Spearman (rs). Estas análises avaliaram a relação existente entre a média mensal das estruturas reprodutivas e os parâmetros climáticos dos meses correntes do período de estudo. As análises foram feitas seguindo procedimentos em Zar (1996), utilizando o aplicativo BioEstat 3.0 (AYRES et al., 2003).

\section{Resultados}

No período de estudo, dois eventos de floração de Syagrus romanzoffiana foram monitorados (Figura 2a). No primeiro evento, que ocorreu de novembro de 2006 a fevereiro de 2007, 43,6\% $(n=17)$ das plantas floresceram, no segundo evento, que ocorreu de outubro de 2007 a março de 2008, 71,8\% (28) das plantas floresceram. A floração apresentou a maior intensidade nos meses de dezembro de 2006 (média $\pm \mathrm{dp})(0,38 \pm 0,63$ inflorescências/planta) 
e janeiro de $2008(0,59 \pm 0,55)$, neste mesmo mês, registramos a maior atividade, com $56,4 \%(n=22)$ das plantas em floração. Quanto à sincronia da floração, no primeiro evento, $41 \%$ das plantas floresceram entre dezembro de 2006 e janeiro de 2007 , no segundo evento, $64,1 \%$ das plantas floresceram entre dezembro de 2007 e janeiro de 2008 (Figura 2a).

FIGURA 2: Representação fenológica baseada no índice de intensidade - - (média mensal de inflorescências ou infrutescências por planta) e no índice de atividade - (porcentagem de indivíduos na fenofase), de Syagrus romanzoffiana (Cham.) Glassman entre junho de 2006 e julho de 2008 no Parque Municipal da Lagoa do Peri, Florianópolis, SC. (A) Inflorescências; (B) Infrutescências verdes e (C) Infrutescências maduras.

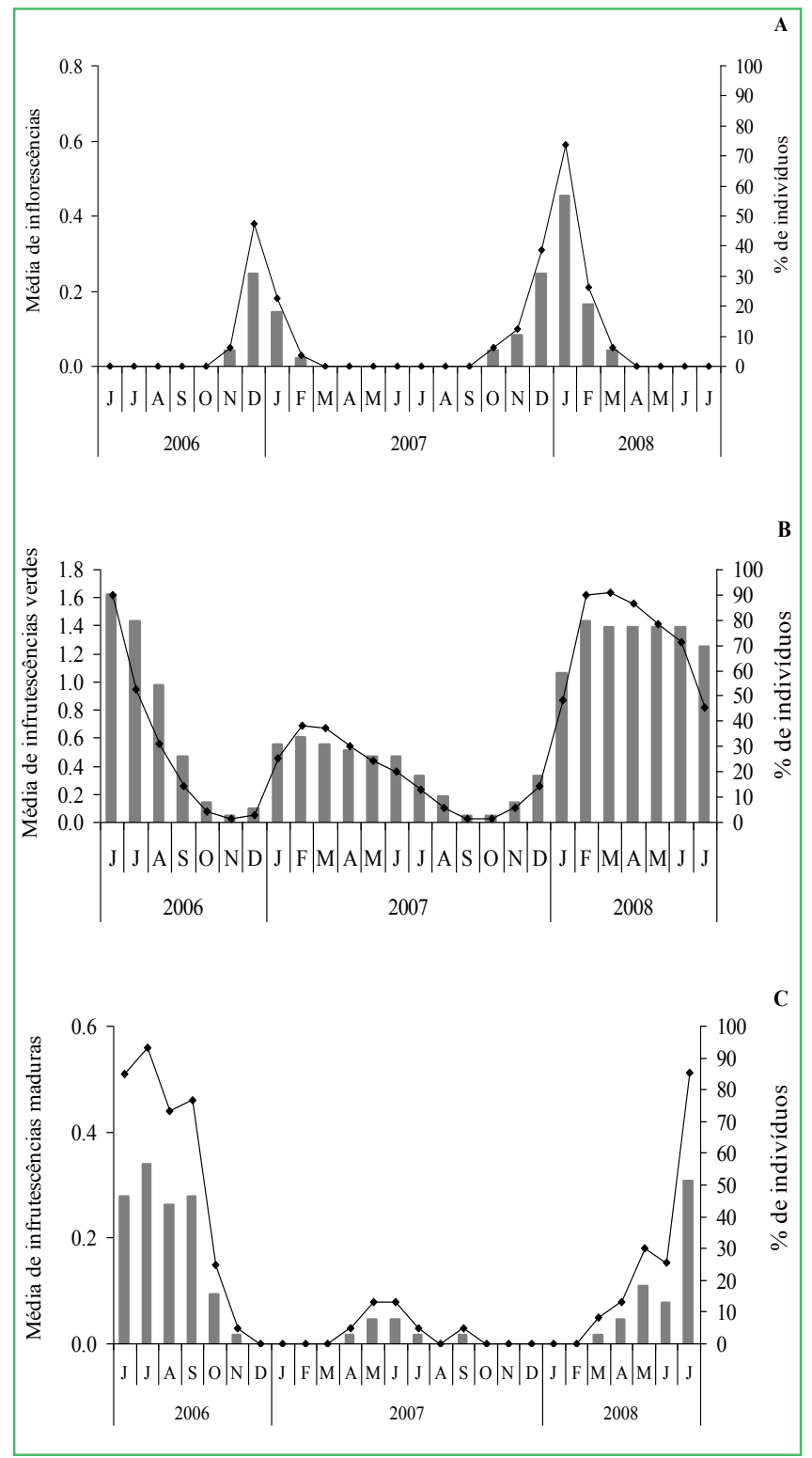

A frutificação foi contínua ao longo dos 26 meses monitorados, com o registro de no mínimo uma planta apresentando infrutescências verdes em cada mês. Março de 2008 apresentou a maior intensidade de infrutescências por planta $(1,64 \pm 1,11)$. No primeiro mês de amostragem, junho de 2006, registramos uma elevada intensidade de infrutescências verdes $(1,62 \pm 0,88)$ e a maior atividade, com $89,7 \%(35)$ plantas com frutos verdes (Figura $2 b$ ).

Os frutos maduros estiveram presentes de forma descontínua, sendo registrados de março a novembro (Figura 2c). Foram evidenciados três eventos distintos com infrutescências maduras nos 26 meses de monitoramento, um evento em 2006, onde se registrou 94,9\% (37) das plantas com infrutescências maduras, outro em 2007, com 17,9\% (7) das plantas com infrutescências maduras e mais um evento em 2008, com $59,0 \%$ (23) das plantas com infrutescências maduras. Em julho de 2006, registramos a maior intensidade de infrutescências maduras por planta $(0,56 \pm 0,50)$ e a maior atividade, com $56,4 \%$ plantas com frutos maduros. Elevado valor de intensidade também ocorreu em julho de $2008(0,51 \pm 0,51)$. Quanto à sincronia das infrutescências maduras na população, destacam-se os meses de julho de 2006 (56,4\% das plantas), junho de 2007 (7,7\%) e julho de 2008 (51,3\%) respectivamente nos três eventos de maturação, como os meses com a maior parte das plantas nesta fenofase. Em 2007 registrou-se uma menor intensidade de frutificação quando comparado com os demais períodos monitorados (Figura 2c).

Quanto à relação existente entre estruturas reprodutivas presentes e os parâmetros climáticos, a média mensal de inflorescências por planta apresentou correlação significativa positiva com as três variáveis climáticas, sendo a maior correlação obtida aquela com o fotoperíodo ( $\mathrm{rs}=0,85, \mathrm{p}<0,05)$ (Tabela 1). As infrutescências verdes não apresentaram correlação significativa com as variáveis climáticas. A média de infrutescências maduras por planta por mês apresentou correlação significativa negativa com as três variáveis climáticas, sendo a correlação mais significativa $(\mathrm{rs}=-0,74, \mathrm{p}<0,05)$ aquela envolvendo o fotoperíodo (Tabela 1). 
TABELA 1: Correlação de Spearmam (rs) entre as inflorescências, infrutescências verdes e infrutescências maduras de Syagrus romanzoffiana (Cham.) Glassman e as variáveis climáticas (fotoperíodo, precipitação e temperatura) do mês corrente, no Parque Municipal da Lagoa do Peri, Florianópolis, SC.

\begin{tabular}{lccc}
\hline \multicolumn{1}{c}{ Fenofases } & Fotoperíodo & Precipitação & Temperatura \\
\hline $\begin{array}{l}\text { Inflorescências } \\
\text { Infrutescências }\end{array}$ & $\mathrm{rs}=0,85^{*}$ & $\mathrm{rs}=0,49^{*}$ & $\mathrm{rs}=0,70^{*}$ \\
$\begin{array}{l}\text { verdes } \\
\text { Infrutescências } \\
\text { maduras }\end{array}$ & $\mathrm{rs}=-0,74^{*}$ & $\mathrm{rs}=-0,04 * *$ & $\mathrm{rs}=0,07 * *$ \\
\hline$* \mathrm{p}<0,05 \mathrm{e} * * \mathrm{p}>0,05$ & $\mathrm{rs}=-0,64 *$ \\
\hline
\end{tabular}

\section{Discussão}

O padrão fenológico do Syagrus romanzoffiana foi considerado anual de acordo com a classificação de Newstrom et al. (1994), uma vez que observamos dois eventos distintos de floração e três eventos distintos de maturação dos frutos nos anos de 2006, 2007 e 2008. O período de floração e de maturação das infrutescências foram considerados sazonais, por apresentarem correlações significativas com o fotoperíodo, precipitação e temperatura dos meses correntes do período de estudo. Esses eventos provavelmente manifestarem-se em resposta a variações desses fatores climáticos, apesar do clima local ser caracterizado como mesotérmico úmido, sem restrição hídrica.

A floração aconteceu no final da primavera e verão, em dois eventos bem definidos temporalmente. Esta sazonalidade pode ser interpretada como uma resposta ao aumento do fotoperíodo, temperatura e precipitação da região. Comportamento semelhante foi observado por Mantovani e Morellato (2000) para a palmeira Euterpe edulis no município de São Pedro de Alcântara, região próxima ao local deste estudo, onde a floração ocorreu entre os meses de outubro e fevereiro, com picos em dezembro e janeiro.

Outros estudos já vêm demonstrando a influência de variáveis climáticas nos eventos fenológicos. Morellato et al. (2000) encontraram correlações positivas do fotoperíodo e da temperatura com a floração em estudos para Florestas Pluviais Atlânticas do Sudeste do Brasil. Talora e Morellato (2000) discutem que mesmo variáveis ambientais pouco sazonais podem exercer influência sobre as fenofases das espécies arbóreas, embora de maneira menos evidente do que em florestas cujo clima apresenta maior sazonalidade.

O ciclo fenológico do S. romanzoffiana apresentou uma sobreposição da floração e da frutificação e uma contínua presença de frutos verdes ao longo do ano. Acreditamos que os frutos verdes permaneceram na população ao longo de todo o processo reprodutivo por apresentarem um período de desenvolvimento de cinco a seis meses até a maturação. Desta forma, não se correlacionam com as variáveis climáticas do período.

A presença de frutos maduros deu-se por até oito meses, março a novembro, evidenciando-se uma fenofase duradoura anualmente, porém com variações na oferta entre os anos e disponibilidade associada ao período de menor fotoperíodo, precipitação e temperatura. Extensos períodos de frutificação foram observados para outras espécies de palmeiras, como para Euterpe edulis em Floresta Ombrófila Densa em Santa Catarina (MANTOVANI; MORELLATO, 2000), para Euterpe oleracea Mart. no estuário amazônico por Jardim e Kageyama (1994) e para Astrocaryum standleyanum L. H. Bailey, Scheelea zonensis L. H. Bailey, Socratea durissima (Oerst.) Wendl. e Bactris major Jacq. em Floresta Tropical no Panamá (DE STEVEN et al., 1987).

As diferenças na intensidade de floração e atividade das plantas dos dois eventos de floração, assim como as diferenças na intensidade de infrutescências maduras e na atividade das plantas entre os três eventos de maturação, sugerem que o comportamento reprodutivo desta palmeira é diretamente influenciado pelas condições climáticas locais. O episódio de redução hídrica, ocorrido no ano de 2006, onde se registraram quatro meses (junho a setembro) com déficit hídrico, segundo os critérios de Wright e van Schaik (1994), possivelmente interferiu na produção e/ou desenvolvimento de inflorescências no primeiro evento de floração acompanhado, bem como no desenvolvimento das infrutescências até a maturação, causando desta forma, uma redução na intensidade e atividade reprodutiva desse período. Segundo Fenner e Thompson (2005), a restrição hídrica pode reduzir o desenvolvimento e o peso dos frutos e sementes. Associado a isto, em junho de 2007, ocorreu 
o menor índice pluviométrico dos últimos 30 anos, o que possivelmente interferiu no amadurecimento dos frutos verdes presentes neste período, comprometendo seu desenvolvimento e a sua maturação.

Variações na intensidade reprodutiva de espécies de palmeiras já foram registradas em outros trabalhos (SARUKHÁN et al. 1984; ROSA et al. 1998), inclusive para S. romanzoffiana por Bernacci et al. (2006). Reis (1995) encontrou em uma área de Floresta Ombrófila Densa primária em Blumenau, Santa Catarina, variações na ordem de $36,4 \%$ e $75,8 \%$ no número de indivíduos florescendo entre dois anos consecutivos em uma mesma população de palmiteiro (E. edulis). Variações individuais também foram registradas na floração do $E$. oleracea por Jardim e Kageyama (1994) e para Butia capitata por Rosa et al. (1998). Essas alternâncias nos eventos reprodutivos de palmeiras podem estar associada a mudanças nas condições climáticas, mas também a outros fatores intrínsecos aos indivíduos, como sua localização, idade e características genéticas (MANTOVANI; MORELLATO, 2000).

Acreditamos que as variações na intensidade reprodutiva e atividade das plantas de $S$. romanzoffiana podem reduzir a oferta de recurso alimentar para a fauna (SILVA et al., 2011), assim como para a entomofauna (SILVA et al., 2012), em anos de baixa produção na população, uma vez que ela é uma das plantas mais frequentes da área avaliada (Daniel Falkenberg comunicação pessoal). Aspectos ligados à dispersão e predação de sementes podem ser relevantes na avaliação do recrutamento e estabelecimento de plântulas desta palmeira em função das variações observadas nos ciclos reprodutivos. Portanto, um acompanhamento mais prolongado do ciclo fenológico do $S$. romanzoffiana é recomendado para a melhor caracterização da existência ou não de eventos de maior e de menor intensidade de produção dessa espécie.

\section{Agradecimentos}

À Universidade Federal de Santa Catarina, pelos dois anos de bolsa de iniciação científica (PIBIC-CNPq) concedida ao primeiro autor, à CAPES pela bolsa concedida à segunda autora e a todos os integrantes do Laboratório de Ecologia Vegetal, ECZ, CCB,UFSC.

\section{Referências}

ALVES-COSTA, C. P. Efeitos da defaunação de mamíferos herbívoros na comunidade vegetal. 2004. 107 f. Tese (Doutorado em Ecologia) - Universidade Estadual de Campinas, Campinas. 2004.

AYRES, M.; AYRES, M. JR.; AYRES, D. L.; SANTOS, A. S. BioEstat 3.0: aplicações estatísticas nas áreas das ciências biomédicas. Belém: Sociedade Civil Mamirauá, 2003. 291 p.

BERNACCI, L. C.; MARTINS, F. R.; SANTOS, F. A. M. Dinâmica populacional da palmeira nativa jerivá, Syagrus romanzoffiana (Cham.) Glassman, em um fragmento florestal no sudeste do Brasil. 2006. Artigo em hipertexto. Disponível em: $<$ http://www. infobibos.com/Artigos/2006_3/jeriva/Index.htm>. Acesso em: 20 abr. 2010

BERNACCI, L. C.; MARTINS, F. R.; SANTOS, F. A. M. Dinâmica populacional da palmeira nativa jerivá, Syagrus romanzoffiana (Cham.) Glassman, em um fragmento florestal no sudeste do Brasil. Acta Botanica Brasilica, Feira de Santana, v. 22, n. 1, p. 119-130, 2008.

BIANCHINI, E.; PIMENTA, J. A.; SANTOS, F. A. M. Fenologia de Chrysophyllum gonocarpum (Mart. \& Eichler) Engl. (Sapotaceae) em floresta semidecídua do sul do Brasil. Revista Brasileira de Botânica, São Paulo, v. 29, n. 4, p. 595-602, 2006.

CALVI, G. P.; RODRIGUES, F. C. M. P. Fenologia e produção de sementes de Euterpe edulis - Mart em trecho de floresta de altitude no município de Miguel Pereira. Revista Universidade Rural, Série Ciências da Vida, Seropédica, v. 25, n. 1, p. 33-40, 2005.

CASTELlANI, T. T.; CAUS, C. A.; VIEIRA, S. Fenologia de uma comunidade de duna frontal no sul do Brasil. Acta Botanica Brasilica, Feira de Santana, v. 13, n. 1, p. 99-114, 1999.

D’EÇA-NEVES, F. F.; MORELlato, L. P. C. Métodos de amostragem e avaliação utilizados em estudos fenológicos de florestas tropicais. Acta Botanica Brasilica, Feira de Santana, v. 18, n. 1, p. 99-108, 2004.

DE STEVEN, D.; WINDSOR, D. M.; PUTZ, F. E.; DE LEON, B. Vegetative and reproductive phenologies of a palm assemblage in Panama. Biotropica, Maiden, v. 19, n. 4, p. 342-356, 1987.

FENNER, M.; THOMPSON, K. The ecology of seeds. Cambridge: Cambridge University Press, 2005. 264 p.

FLEURY, M.; GALETTI, M. Effects of microhabitat on palm seed predation in two forest fragments in southeast Brasil. Acta Oecologica, New York, v. 26, p. 179-184, 2004.

GALETTI, M.; KEUROGHLIAN, A.; HANADA, L.; MORATO, M. I. Frugivory and seed dispersal by the lowland tapir (Tapirus terrestris) in southeast Brazil. Biotropica, Maiden, v. 33, p. $723-$ 726, 2001.

GALETTI, M.; PASCHOAL, M.; PEDRONI, F. Predation on palms nuts (Syagrus romanzoffiana) by squirrels (Sciurus ingrami) in south-east Brazil. Journal of Tropical Ecology, Winchelsea, v. 8, n. 1, p. 121-123, 1992.

GENINI, J.; GAlETTI, M.; MORELlATO, L. P. C. Fruiting phenology of palms and trees in an Atlantic rainforest land-bridge island. Flora, Jena, v. 204, p. 131-145, 2009.

GIOMBINI, M. I.; BRAVO, S. P.; MARTÍNEZ, M. F. Seed dispersal of the palm Syagrus romanzoffiana by tapirs in the Semideciduous Atlantic Forest of Argentina. Biotropica, Maiden, v. 41, n. 4, p. 408-413, 2009. 
GUIX, J. C.; RUIZ, X. Plant-disperser-pest evolutionary triads: how widespread are they? Orsis, Barcelona, v. 15, p. 121-126, 2000.

HENDERSON, A.; FISCHER, B.; SCARIOT, A.; PACHECO, M. A. W.; PARDINI, R. Flowering phenology of a palm community in a central Amazon Forest. Brittonia, New York, v. 52, n. 2, p. 149-159, 2000.

JARDIM, M. A. G.; KAGEYAMA, P. Y. Fenologia de floração e frutificação em população natural de açaizeiro (Euterpe oleracea Mart.) no estuário amazônico. Instituto de Pesquisas e Estudos Florestais, Piracicaba, v. 47, p. 62-65, 1994.

LORENZI, H. Árvores brasileiras - Manual de identificação e cultivo de plantas arbóreas nativas do Brasil. 4 ed. Nova Odessa: Instituto Plantarum, 2002. 368 p.

LORENZI, H. Palmeiras brasileiras e exóticas cultivadas. Nova Odessa: Instituto Plantarum, 2004. 160 p.

MANTOVANI, A.; MORELLATO, L. P. C. Fenologia da floração, frutificação, mudança foliar e aspectos da biologia floral do palmiteiro Euterpe edulis (Arecaceae). Sellowia, Itajaí, v. 49-52, p. 23-38, 2000.

MANTOVANI, M.; RUSCHEL, A. R.; REIS, M. S.; PUCHALSKI, A.; NODARI, R. O. Fenologia reprodutiva de espécies arbóreas em uma formação secundária da floresta atlântica. Revista Árvore, Viçosa, v. 27, n. 4, p. 451-458, 2003.

MORELLATO, L. P. C.; LEITÃO-FILHO, H. F. Estratégias fenológicas de espécies arbóreas em floresta mesófila na Serra do Japi. Revista Brasileira de Biologia, v. 50, p. 163-173, 1990.

MORELlATO, L. P. C.; TALORA, D. C.; TAKAHASI, A.; BENCKE, C. S.; ROMERA, E. C.; ZIPPARRO, V. B. Phenology of Atlantic rain forest trees: a comparative study. Biotropica, Maiden, v. 32, n. 4b, p. 811-823, 2000

NEWSTROM, L. E.; FRANKIE, G. W., BAKER, H. G. A new classification for plant phenology based on flowering patterns in lowland tropical forest trees at La Selva, Costa Rica. Biotropica, Maiden, v. 26, n. 2, p. 141-159, 1994.

OLMOS, F.; PARDINI, R.; BOULHOUSA, R. L. P.; BÜRGI R.; MORSELLO, C. Do tapirs steal food from palm seed predators or give them a lift? Biotropica, Maiden, v. 31, n. 2, p. 375-379, 1999. PEDRONI, F.; SANCHEZ, M.; SANTOS, F. A. M. Fenologia da copaíba (Copaifera langsdorffii Desf. - Leguminosae, Caesalpiniodeae) em uma floresta semidecídua no sudeste do Brasil. Revista Brasileira de Botânica, São Paulo, v. 25, n. 2, p. 183-194, 2002.

PERES, C. A. Identifying keystone plant resources in tropical forests: the case of gums from Parkia pods. Journal of Tropical Ecology, Winchelsea, v. 16, n. 2, p. 287-317, 2000.

PIÑERO, D.; SARUKHÁN, J. Reproductive behaviour and its individual variability in a tropical palm, Astrocaryum mexicanum. Journal of Ecology, London, v. 70, n. 2, p. 461-472, 1982.

RATHCKE, B.; LACEY, E. P. Phenological patterns of terrestrial plants. Annual Review of Ecology and Systematics, Palo Alto, v. 16, p. 179-214, 1985.

REIS, A.; KAGEYAMA, P. Y. Restauração de áreas degradadas utilizando interações interespecíficas. In: KAGEYAMA, P. Y.; OLIVEIRA, R. E.; ENGEL, V. L.; GANDARA, F. B. (Ed.). Restauração ecológica de ecossistemas naturais. Botucatu: Fundação de Estudos e Pesquisas Agrícolas e Florestais, 2003. p. 91-110.
REIS, A. Dispersão de sementes de Euterpe edulis Martius - (Palmae) em uma Floresta Ombrófila Densa Montana da encosta atlântica em Blumenau, SC. 1995. 154 f. Tese (Doutorado em Biologia Vegetal) - Universidade Estadual de Campinas, Campinas. 1995.

ROSA, L.; CASTELLANI, T. T.; REIS, A. Biologia reprodutiva de Butia capitata (Martius) Beccari var. odorata (Palmae) na restinga do município de Laguna, SC. Revista Brasileira de Botânica, São Paulo, v. 21, n. 3, p. 281-287, 1998.

RUIZ, R. R.; ALENCAR, J. C. Comportamento fenológico da palmeira patauá (Oenocarpus bataua) na reserva florestal Adolpho Ducke, Manaus, Amazonas, Brasil. Acta Amazonica, Manaus, v. 34, n. 4, p. 553-558, 2004.

SANTOS, D. L.; TAKAKI, M. Fenologia de Cedrela fissilis Vell. (Meliaceae) na região rural de Itirapina, SP, Brasil. Acta Botanica Brasilica, Feira de Santana, v. 19, n. 3, p. 625-632, 2005.

SARUKHÁN, J.; MARTÍNEZ-RAMOS, M.; PIÑERO, D. The analysis of demographic variability at the individual level and its populational consequences. In: DIRZO, R.; SARUKHÁN, J. (Ed.). Perspectives on plant population ecology. Sunderland: Sinauer Associates Inc., 1984. p. 83-106.

SILVA, A. A. S. Parque Municipal da Lagoa do Peri: subsídios para o Gerenciamento Ambiental. 2000. 130 f. Dissertação (Mestrado em Engenharia de Produção) - Universidade Federal de Santa Catarina, Florianópolis. 2000.

SILVA, F. R.; BEGNINI, R. M.; LOPES, B. C.; CASTELLANI, T. $\mathrm{T}$. Seed dispersal and predation in the palm Syagrus romanzoffiana on two islands with different faunal richness, southern Brazil. Studies on Neotropical Fauna and Environment, Tübingen, v. 46, n. 3, p. 163-171, 2011.

SILVA, F. R.; BEGNINI, R. M.; LOPES, B. C.; CASTELLANI, T. $\mathrm{T}$. Temporal variation in seed predation by insects in a population of Syagrus romanzoffiana (Arecaceae) in Santa Catarina Island, SC, Brazil. Neotropical Entomology, Sociedade Entomológica do Brasil, v. 45, n. 1, p. 17-21, 2012.

SIMONASSI, J. C. Caracterização da Lagoa do Peri, através da análise de parâmetros físico-químicos e biológicos, como subsídio ao gerenciamento dos recursos hídricos da Ilha de Santa Catarina, SC, Brasil. 2001. 72 f. Dissertação (Mestrado em Engenharia de Produção) - Universidade Federal de Santa Catarina, Florianópolis. 2001.

TALORA, D. C.; MORELlATO, L. P. C. Fenologia de espécies arbóreas em floresta de planície litorânea do sudeste do Brasil. Revista Brasileira de Botânica, São Paulo, v. 23, n. 1, p. 13-26, 2000.

TONHASCA JR., A. Ecologia e história natural da Mata Atlântica. Rio de Janeiro: Interciência, 2005. 198 p.

WRIGHT, S. J.; VAN SCHAIK, C. P. Light and the phenology of tropical trees. The American Naturalist, Chicago, v. 143, n. 1, p. 192-199, 1994.

ZAR, J. H. Biostatistical analysis. 3 ed. New Jersey: Prentice Hall, 1996. 620 p.

ZIMMERMANN, T. G.; BEGNINI, R. M.; SILVA, F. R. Syagrus romanzoffiana (Jerivá). In: CORADIN, L.; SIMINSKI, A.; REIS, A. (Org.). Espécies nativas da flora brasileira de valor econômico atual ou potencial: plantas para o futuro - Região Sul. Brasília: MMA, 2011. p. 812-819. 